\title{
PROCESSOS PRODUTIVOS DE SINAIS NOCIONALMENTE NOMES NA LIBRAS
}

\author{
PRODUCTIVE PROCESSES OF SIGNS NOTIONALLY NOUNS IN LIBRAS \\ PROCESOS PRODUCTIVOS DE SEÑAS NOCIONALMENTE \\ NOMBRES EN LIBRAS
}

Hildomar José Lima*

\section{Resumo}

Este artigo tem como objetivo apresentar considerações sobre sinais utilizados pela Língua de Sinais Brasileira (Libras) que se correlacionam nocionalmente com nomes no português brasileiro. As observações se deram com base nas características semânticas prototípicas para a definição da categoria lexical "nome", propostas por Givón (2001). Ao considerar especialmente a modalidade visuoespacial dessa língua, imagina-se a dimensão como critério semântico de relevância, pois é através dela que são descritas diversas entidades. Sugerem-se três processos produtivos de sinais nocionalmente nomes nessa língua, com base em suas características semânticas: a representação espacial das entidades, sinais que inserem a letra inicial da palavra em português na sua forma, e a datilologia como recurso para a formação de sinais.

Palavras-chave: Libras, Características semânticas, Noção nominal.

\section{Introdução}

Ainda há poucos estudos descritivos da Língua de Sinais Brasileira (Libras) e, portanto, ainda não se tem critérios gramaticais claros quando a tarefa é definir categorias lexicais nessa língua. Em relação à categoria nome, Quadros e Karnopp (2004) sugerem a natureza do movimento como uma propriedade gramatical para possível identificação dessa classe na Libras. O padrão regular observado foi que, nos nomes, há uma repetição e um encurtamento do movimento em relação aos verbos, que tendem a apresentar um movimento mais alongado e sem repetição.

\footnotetext{
* Doutorando em Estudos Linguísticos pela Universidade Federal de Goiás. Professor do Departamento de Libras e Tradução da Faculdade de Letras / UFG. E-mail: hildomarlima@ gmail.com
} 
No entanto, um estudo realizado por Pizzio (2011) mostrou que não há regularidades na ocorrência do movimento para a definição de critérios relevantes na distinção entre as categorias nome e verbo na Libras e, consequentemente, na definição das propriedades que definem cada uma. Pizzio observou especialmente a diferença entre alguns pares como "telefone" e "telefonar" com base na repetição do movimento e concluiu que não foi possível observar um padrão de produção que os diferenciasse, visto que mais da metade dos participantes da pesquisa $(58,62 \%)$ utilizou o mesmo sinal para ambos. Nesse e em outros casos, o número de movimentos não foi elemento diferenciador entre tais categorias.

Neste artigo, pretende-se explicitar algumas observações preliminares sobre sinais da Libras que se correlacionam nocionalmente com a categoria lexical "nome" no português do brasileiro. A observação parte das características semânticas prototípicas para a definição da categorial lexical "nome”, propostas por Givón (2001). São prototípicas as propriedades mais específicas e que definem uma categoria. Nesse sentido, um nome se constitui com base em traços mais peculiares para essa classe e menos para outras, ou seja, suas propriedades o tornam mais nome e menos verbo.

Cumpre esclarecer que para Givón, o nome geralmente não se define com base apenas nas características semânticas. Em muitas línguas, as propriedades sintáticas e morfológicas são imprescindíveis para estabelecer essa classe lexical. Uma entidade poderá apresentar os seguintes traços semânticos: abstrato - temporal > não especial - espacial > inanimado - animado > não humano - humano > feminino - masculino.

Essas características distinguem o que é estável daquilo que é dinâmico no universo conceitual. Uma criança, por exemplo, num percurso natural se torna adolescente, em seguida adulto, porém algumas propriedades serão mantidas (humano - animado - existe no espaço - existe no tempo = entidade). Entende-se por entidade tudo aquilo que existe no universo conceitual.

A partir de observações de alguns exemplos da Libras (ex.: PRÉDIO, ÁRVORE etc.), e considerando especialmente a modalidade visuoespacial, propõe-se a "dimensão" como um traço de relevância para a identificação de alguns sinais nocionalmente nomes 
nessa língua. Sugere-se, portanto, que a forma da entidade constitui uma característica semântica nas línguas de sinais.

\section{Características semânticas prototípicas dos nomes}

De acordo com Givón (2001), algumas categorias lexicais nas línguas se definem, inicialmente, a partir de critérios semânticos básicos, que apresentam características mais genéricas ou classificatórias do léxico conceitual. Os traços presentes em cada critério exibem fortes associações entre si, de modo que cada característica é parcialmente previsível dentro dos diferentes critérios.

Em cada um desses critérios semânticos podem-se encontrar gradações, de forma que os itens pertencentes a cada categoria se agrupam em termos de "maior" ou de "menor" prototipicidade. Isso significa que, muito provavelmente na categoria nome, por exemplo, teremos aqueles itens que são "mais prototípicos" e aqueles que são "menos prototípicos" dentro de um mesmo conjunto de critérios semânticos (GIVÓN, 2001). Esse autor propõe como traços semânticos:

I. Estabilidade temporal: as propriedades de uma entidade alteram-se muito pouco na percepção das cenas de um evento. Uma "cadeira”, por exemplo, continuará sendo a mesma entidade daqui a cinco minutos, uma hora, um dia (em relação à cor, textura, utilidade). É necessário que se considerem as pequenas gradações; no entanto, uma cadeira não se converterá em prédio.

II. Complexidade: está relacionada à grande estabilidade temporal do protótipo nome. O nome "cavalo", por exemplo, apresenta várias características de composição (tamanho, cor, forma ou peso), bem como predisposições comportamentais e usos culturais que são atributos prototípicos da entidade. Nesse sentido, caso aconteça alguma mudança ou desvio rápido em uma característica, a estabilidade relativa das demais características assegura que a entidade permaneça na categoria.

III. Concretude: há entidades constituídas de materiais relativamente duráveis. Propriedades como tamanho, cor, forma ou consistência mudam relativamente devagar. Sendo assim, caracterizam-se como mais prototípicos os "nomes" que 
remetem a entidades palpáveis (concretas) e menos prototípicos aqueles que remetem a conceitos não palpáveis (abstratos).

IV. Compacidade espacial: refere-se à coerência espacial das entidades que ocupam um “espaço contíguo" e não espalhado no campo da percepção. No caso dos nomes que ocupam um "espaço espalhado" (celebração, terça-feira, chuva), esses tendem a ser não prototípicos também em termos de concretude e estabilidade temporal.

V. Contabilidade: os nomes contáveis tendem a ser relativamente pequenos e consequentemente compactos, ocupando assim uma pequena porção do campo perceptivo total. Taylor (2002) denomina figura-fundo o modo de percepção em que se distingue de forma adequada uma entidade e o espaço em que ela ocupa na apresentação de um campo visual.

Sugere-se, portanto, a dimensão como uma extensão do traço compacidade. A dimensão constitui critério que se aplica com grande precisão às línguas de sinais, dada à modalidade visual dessas línguas. Vários de sinais da Libras exploram a dimensão das entidades para poder representá-las. O sinal ARMÁRIO DE ROUPAS (Fig.1), por exemplo, descreve as partes da entidade de modo que é possível visualizá-la a partir de diferentes ângulos (uma visão bi ou tridimensional).

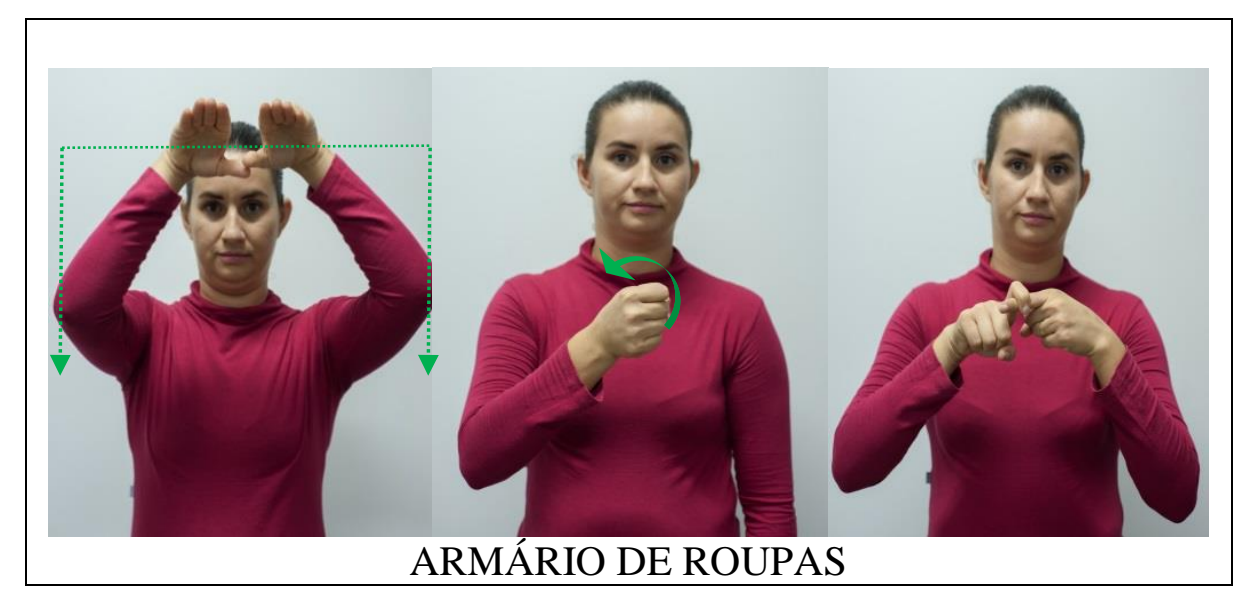

Figura 1. Ilustração do sinal ARMÁRIO DE ROUPAS ${ }^{1}$. 
Em ARMÁRIO DE ROUPAS, uma variedade encontrada em Goiás, descrevem-se as características físicas externas da entidade, no caso o formato, iniciando pela parte superior; em seguida, as partes laterais e, por último, descreve a função do móvel (guardar as roupas), uma característica interna da entidade.

A descrição espacial de alguns sinais possibilita uma visão ora bidimensional (altura e largura ou comprimento), ora tridimensional (altura, largura ou comprimento e profundidade) da entidade.

\section{Representação espacial das entidades}

A modalidade linguística visuo-espacial oferece maiores condições visuais de se perceber a motivação icônica na forma linguística. Nessas línguas, a relação existente entre "forma" e "sentido" é mais visual, em relação às línguas orais, ou seja, o ícone resulta, geralmente, de características do objeto que representa (SALLES, 2004; TEIXEIRA, 2014). A descrição espacial das entidades pode ocorrer no espaço neutro de sinalização ou em contato com partes específicas do corpo.

Alguns sinais da Libras que nomeiam entidades com traços de estabilidade temporal se caracterizam por representá-las como um todo, conforme se observa nos sinais DOMINÓ e CHAVE DE FENDA (Fig. 2).

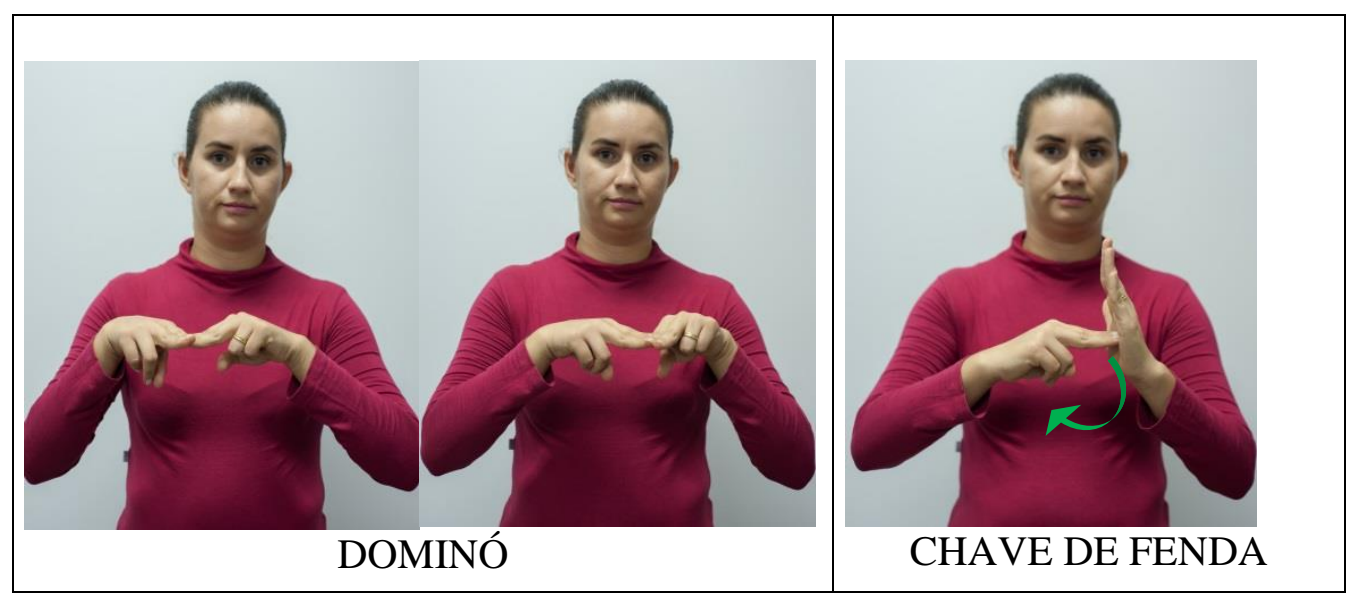

Figura 2. Ilustração dos sinais DOMINÓ e CHAVE DE FENDA. 
No sinal DOMINÓ, dedos indicador e médio de ambas as mãos estendidos e demais dedos fechados, palmas para baixo, pontas dos dedos da mão esquerda voltadas para frente, tocando a lateral do indicador da mão direita (em seguida, alterna com a outra mão). Essa configuração de mão remete ao formato retangular das peças do dominó. Em CHAVE DE FENDA, a mão direita apresenta estendidos os dedos, indicador e médio e demais dedos fechados, palma para baixo, com as pontas dos dedos tocando a palma da mão esquerda. Nesses exemplos, verifica-se que os sinais descrevem a entidade como um todo. Em DOMINÓ cada uma das mãos representa uma peça do jogo e em CHAVE DE FENDA os dedos remetem à ponta do instrumento, enquanto o antebraço parece indicar o cabo da ferramenta.

Essas características de composição podem ser observadas em outros sinais, como: ÁRVORE, os galhos e o tronco; CÂMERA FOTOGRÁFICA, movimento com a ponta do dedo indicador (clique para tirar uma foto); CASA, representação do telhado etc.

Diversos sinais que nomeiam entidades com traços de complexidade expressam aspectos físicos de sua composição. Termos que nomeiam animais, por exemplo, caracterizam-se por representar partes do corpo e em sua maioria localizam-se no espaço de abrangência do membro superior, como é possível observar nos sinais CAVALO/ÉGUA e BOI/VACA (Fig. 3).

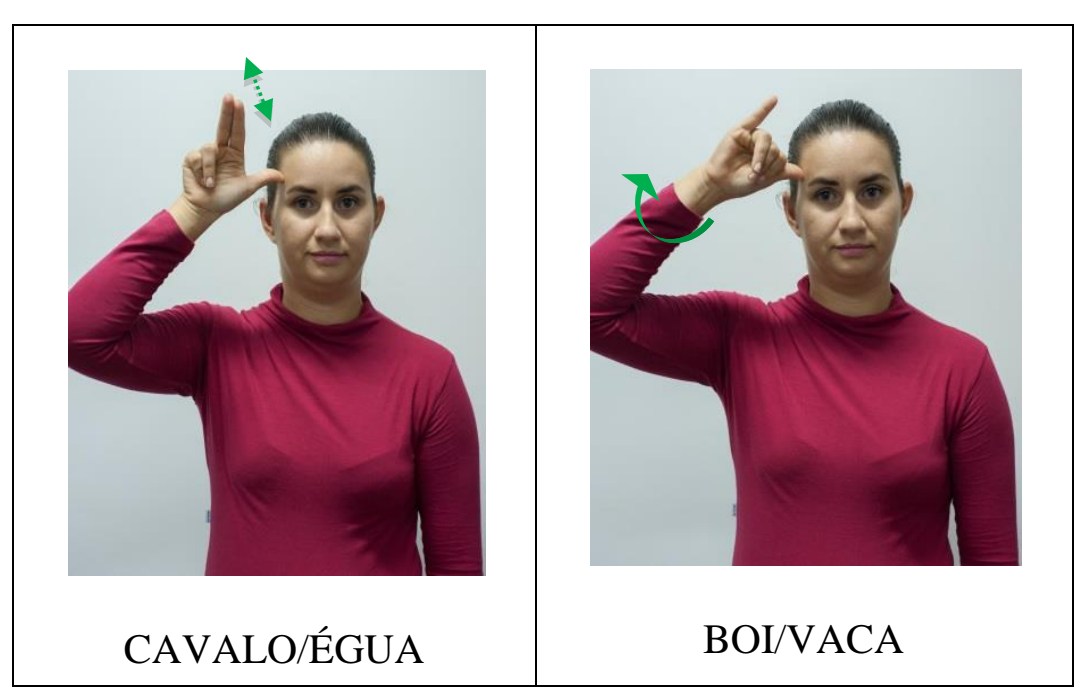

Figura 3. Ilustração dos sinais CAVALO/ÉGUA e BOI/VACA. 
No sinal CAVALO/ÉGUA, a mão assume uma configuração que remete ao formato da orelha do animal. Em VACA/BOI, percebe-se uma forma que representa o chifre. Exemplos de outros sinais para animais em que se descrevem características físicas: GALO/GALINHA, a crista; PATO/A, o bico; CÃO/CADELA, o focinho; JACARÉ, a boca; GIRAFA, o pescoço; ELEFANTE, a tromba; PÁSSARO (em geral), o bico.

A descrição de partes da entidade é uma característica também comum nos sinais que nomeiam meios de transportes. Observe-se nas formas: AUTOMÓVEL e BICICLETA (Fig. 4).

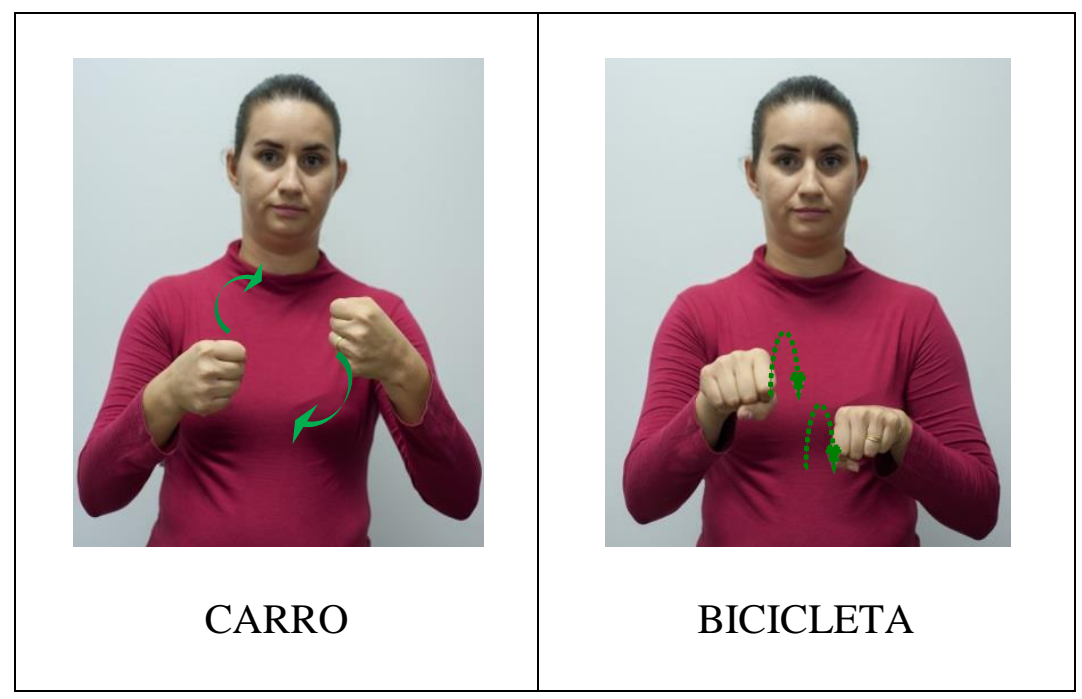

Figura 4. Ilustração dos sinais CARRO e BICICLETA.

No sinal AUTOMÓVEL, elege-se uma peça, o volante, localizada no interior da entidade, para representá-la. Em BICICLETA, as mãos em S, palma para baixo e movendo alternadamente em círculos verticais para frente faz menção os pedais do veículo de duas rodas. Interessante observar que a maioria dos sinais que nomeiam meios de transportes envolve um movimento característico, que parece indicar a entidade em estado de movimento. Em AUTOMÓVEL, o giro circular parece indicar a entidade em estado de movimento. O mesmo ocorre em BICICLETA. 
Entre os sinais que nomeiam meios de transporte a partir da representação de parte da entidade estão: HELICÓPTERO, representado pela hélice; AVIÃO, pelas asas; CANOA, pelo remo e MOTOCICLETA, representada pelas mãos em posição de segurar o guidão e um movimento rotativo com a mão direita, para indicar aceleração.

A representação icônica é muito produtiva também naqueles sinais que apresentam traços de concretude. Os sinais que nomeiam plantas, objetos e animais, por exemplo, geralmente apontam ou descrevem uma característica física da entidade, conforme se verifica em GARFO DE MESA e BARATA (Fig.5).

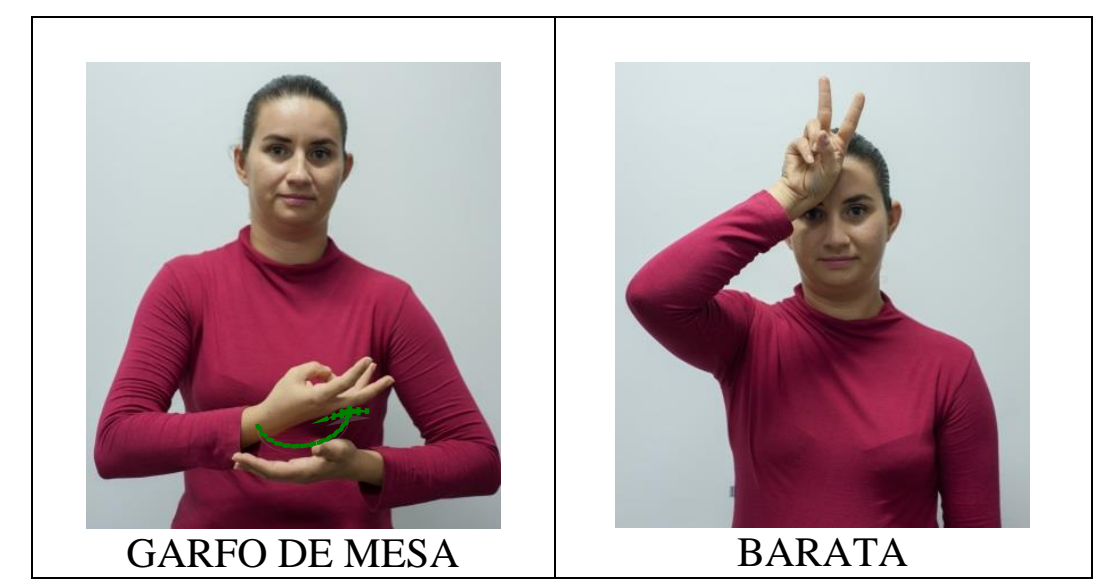

Figura 5. Ilustração dos sinais GARFO DE MESA e BARATA.

Em GARFO DE MESA, a mão direita com os dedos indicador, médio e anelar estendidos toca a superfície da mão esquerda. Essa configuração lembra os dentes do garfo, com o antebraço sugerindo o cabo, enquanto o movimento remete à idéia / ação de levar, com o garfo, o alimento à boca. A superfície da mão esquerda sugere a representação prato. No sinal BARATA, toca-se a testa com a mão direita, palma para frente, dedos indicador e médio estendidos, com movimentos alternados, como as antenas do inseto.

A descrição do objeto ou de parte dele é igualmente usual no processo de nomeação de profissionais, conforme se observa em ENGENHEIRO e JORNALISTA (Fig. 6). 


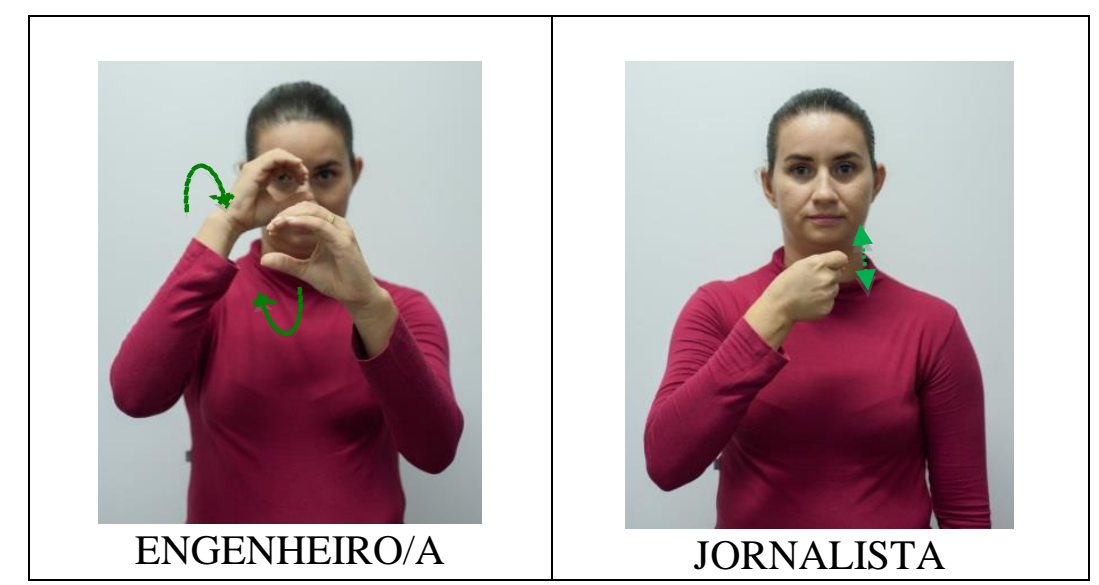

Figura 6. Ilustração dos sinais ENGENHEIRO/A e JORNALISTA.

O sinal ENGENHEIRO descreve o formato característico do binóculo de longo alcance, utilizado por esse profissional. O movimento semicircular reproduz o manuseio do instrumento. Em JORNALISTA, a mão direita exibe uma configuração que faz referência a uma pessoa que segura o microfone e o movimento remete à ideia de uma entrevista.

Nos sinais para as profissões parece haver uma relação de empatia entre o especialista de uma área e seu instrumento de trabalho. Percebe-se essa relação nos seguintes sinais: ÁRBITRO, o apito; ARQUITETO/A, a régua; CABELEIREIRO/A, a tesoura; COZINHEIRO/A, o mexer uma panela com a colher; MECÂNICO/A, o ato de parafusar; PEDREIRO/A, o assentar tijolos.

Vários sinais da Libras que exploram a "dimensão" da entidade são representados a partir de suas características físicas, conforme se observa nos sinais ÁRVORE e GELADEIRA (Fig. 7). 


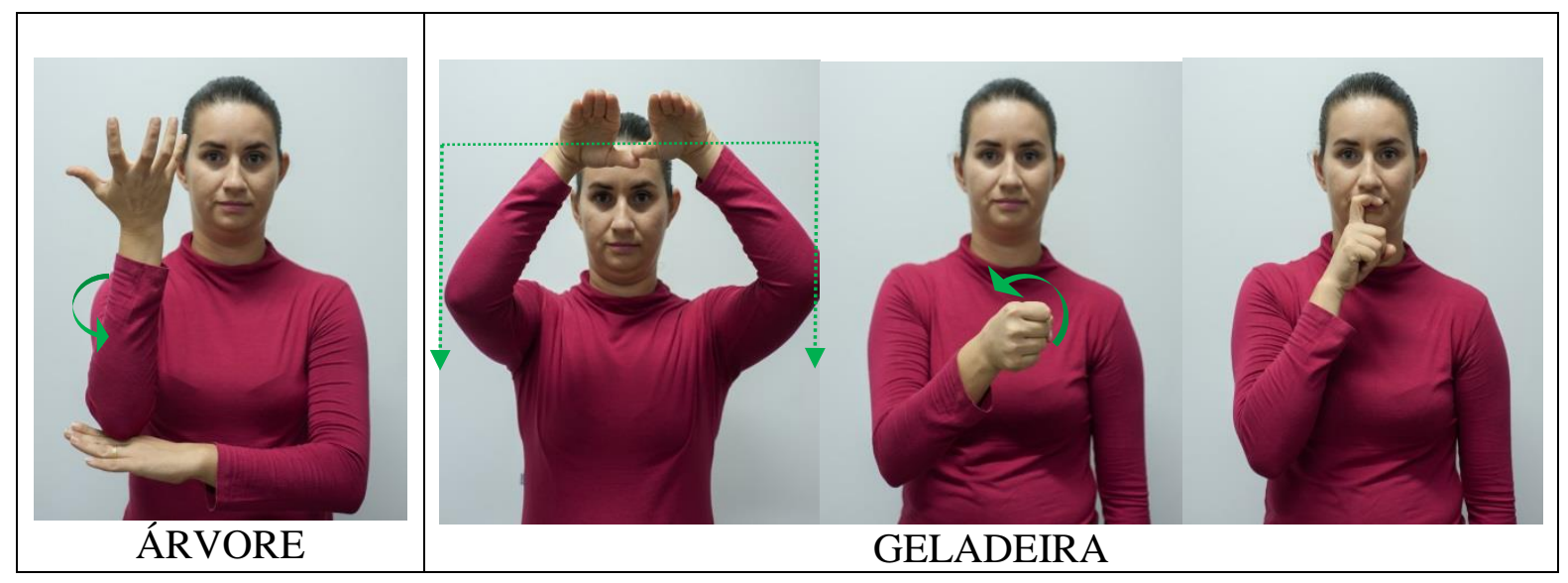

Figura 7. Ilustração dos sinais ÁRVORE e GELADEIRA.

Em ÁRVORE, a entidade é descrita em suas partes principais (galhos e tronco). O antebraço representa o tronco, enquanto os dedos estendidos, juntamente com formato da mão, indicam a copa. No sinal GELADEIRA (uma variedade encontrada em Goiás), observa-se a descrição de características de composição do eletrodoméstico, bem como a indicação de sua utilidade. Ambos os sinais envolvem movimentos que permitem visualizar as entidades em diferentes dimensões. No primeiro, avista-se a entidade por diferentes ângulos a partir da mudança na orientação da palma da mão. No segundo, a descrição permite conceber a entidade de forma bidimensional (a altura e a largura).

Exemplos de outros sinais da Libras que seguem o mesmo padrão de composição para nomear móveis e eletrodomésticos: ARMÁRIO DE COZINHA, descrevem-se as partes superior e laterais; MESA, a superfície e as pernas; CAMA, as pernas; FOGÃO, a superfície, as laterais e as chamas. Nos sinais para eletroeletrônicos é usual a descrição de características do objeto como em TELEVISÃO, representa-se o formato da tela; APARELHO DE SOM, o sinal 'som' acrescido da descrição de ligar o aparelho etc.

\section{Sinal que insere na sua forma a letra inicial da palavra em português}

Na Libras, uma série de sinais nocionalmente nomes se utiliza de propriedades internas constitutivas do português. Esses termos são produzidos com uma configuração de mão (CM) que exibe, convencionalmente, relação de similaridade com letras do alfabeto da 
língua oral, que co-ocorre com um movimento próprio. Faria-Nascimento (2009, p. 66) denomina esse processo de "empréstimo por transliteração da letra inicial" (doravante ETLI) e observa que "apesar de o sinal se constituir com a CM da letra inicial da palavra em português, todo o processo de construção do sinal segue, rigorosamente, as regras de construção lexical da Libras".

O ETLI trata de um "empréstimo de fronteira", pois se refere à forma híbrida, que não é puramente datilológica, nem puramente fruto de uma construção autônoma.Para Nascimento (2011, p. 47), a influência do código escrito do português na criação dos sinais é "encoberta" por um tipo de adaptação "morfofonológica", de modo que os elementos de origem em certos sinais só serão recuperados em análises diacrônicas. Há casos em que inexiste a relação de similaridade entre a CM e a letra inicial da palavra que nomeia a entidade em português, como é o caso do sinal DIRETOR/A em que a CM se assemelha ao "r" e não em "d" como é de se esperar.

Esse processo de constituição é verificado em sinais que apresentam traços de concretude e é bastante produtivo na nomeação de lugares, especialmente quando se trata de cidades do estado de Goiás, conforme se observa no sinal GOIÂNIA (Fig. 8).

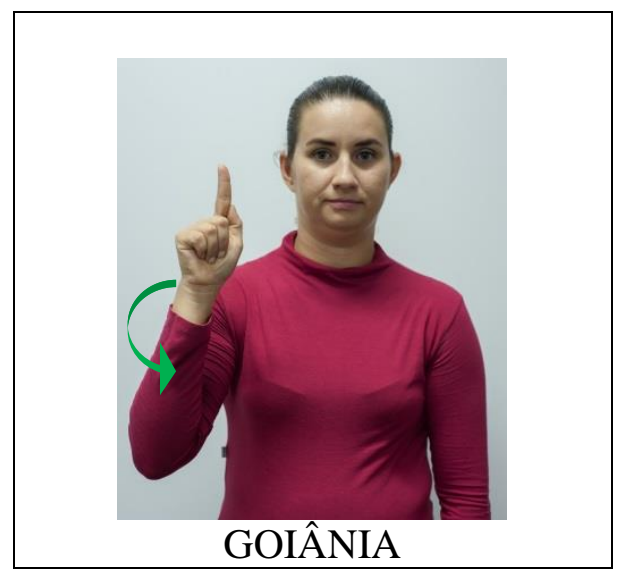

Figura 8. Ilustração do sinal GOIÂNIA. 
Em GOIÂNIA, a mão direita assume uma configuração que, convencionalmente, exibe similaridade com a letra "g" do alfabeto do português, acrescida de um movimento semicircular do antebraço.

O ETLI é um processo comum também em sinais que nomeiam profissionais ou funções, conforme se observa nos sinais PROFESSORA/A e COORDENADOR/A (Fig. 9).

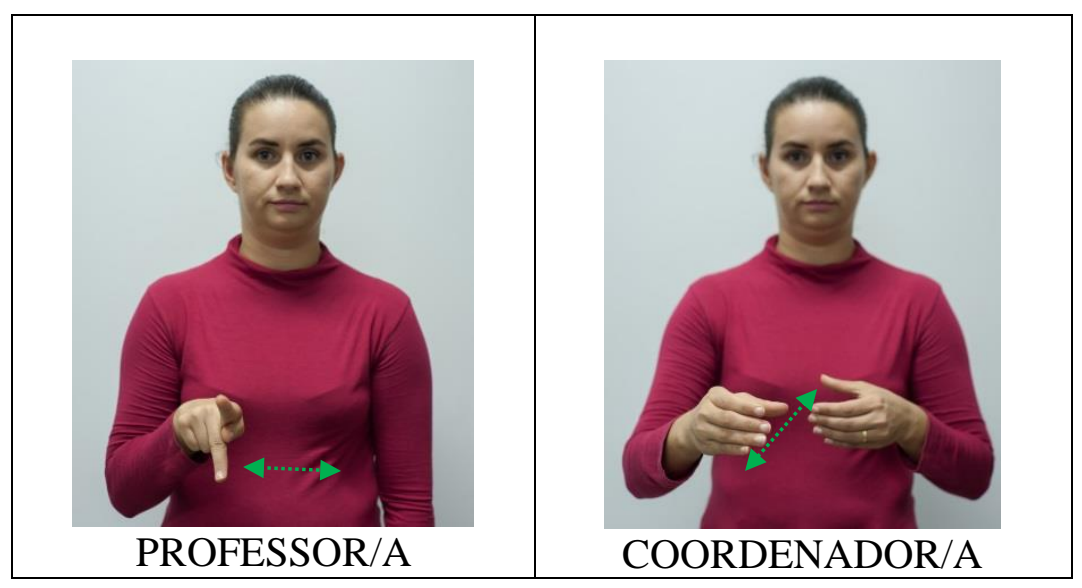

Figura 9. Ilustração dos sinais PROFESSOR/A e COORDENADOR/A.

No sinal PROFESSOR/A, a CM denota equivalência com a letra "p". Essa CM ganha um movimento próprio (sai da esquerda para a direita, na perspectiva de quem produz o sinal). Em COORDENADOR/A, a similaridade ocorre com a letra "c" e o acréscimo de um movimento para frente e para trás. Exemplos de outros sinais que nomeiam funções ou profissionais diversos a partir do ETLI: GERENTE, "g"; PRESIDENTE, “p”; BIÓLOGO, “b”; INSTRUTOR, “i”; VEREADOR, “v”.

Verifica-se que o ETLI é uma característica de composição daqueles sinais menos prototípicos, em termos de compacidade espacial. No sinal FAMÍLIA (Fig. 10), as mãos apresentam similaridades com o "f". 


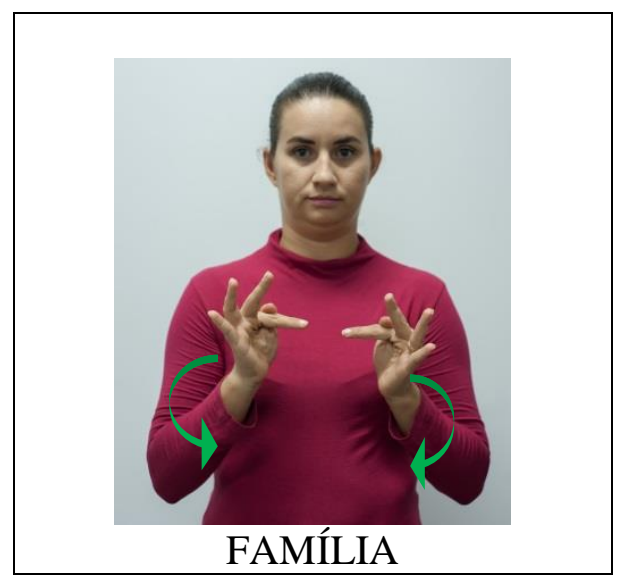

Figura 10. Ilustração do sinal FAMÍLIA.

Esse processo de produção é comum também em sinais para meses do ano, por exemplo: JANEIRO, “j”; FEVEREIRO, “f”; ABRIL, “a” etc. Não seguem o mesmo padrão de composição os meses junho, setembro e dezembro, pois são relacionados a eventos ou personagens tomados como referência nos respectivos meses: fogueira para comemoração de festas juninas, marcha militar em comemoração ao dia 7 de setembro e a barba de Papai Noel, como símbolo do evento festivo do dezembro. Outros exemplos com a mesma característica: FELICIDADE, “f”; DEPRESSÃO, “d”; PAZ, “p”; DOMINGO, “d”; FÉRIAS, “f”; CONHECIMENTO, “c” etc.

Outra característica dos sinais da Libras não prototípicos, em termos de compacidade, é o fato de compartilharem campos semânticos específicos. Esses campos estão divididos por regiões do corpo, as quais podem apresentar subdivisões. Na região torácica, por exemplo, temos aqueles sinais que têm o ponto de articulação (PA) mais ao centro como em PRAZER (bem-estar), ESTRESSE, DEPRESSÃO. Nessa mesma região tem-se os termos produzidos mais à esquerda (região do coração) como AMOR, ROMANCE, ÓDIO, RANCOR, AMIZADE.

Entre outras regiões que apresentam subdivisões, na cabeça são produzidos sinais na testa, como: FÁCIL, DIFÍCIL, INVENÇÃO, APRENDIZAGEM, ARREPENDIMENTO, ESQUECIMENTO e na têmpora, como em: PENSAMENTO, INTELIGÊNCIA, REFLEXÃO. Esses últimos compartilham o fato de ser resultado de alguma atividade mental (atenção, memória, percepção, raciocínio). 
O ETLI é comum em sinais que apresentam traços de dimensão. Observe-se no sinal CÉU (Fig. 11).

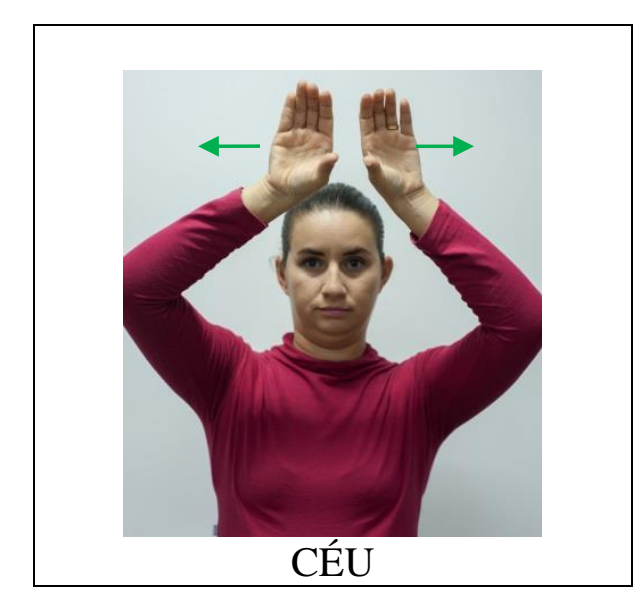

Figura 11. Ilustração do sinal CÉU.

Em CÉU, as mãos em “c”, palmas para frente, acima da cabeça, movendo-se para lados opostos. Nesse sinal verifica-se, como característica de dimensão, a altura (mãos acima da cabeça) e a largura (direção em lados opostos). Exemplos de outros sinais da Libras que apresentam traços de dimensão: GEOGRAFIA, "g"; CONGRESSO, "c" e SEMINÁRIO, "s".

\section{A datilologia como recurso para a formação de sinais}

A datilologia constitui um processo produtivo de sinais nocionalmente nomes na Libras. Esse recurso é aqui entendido como a representação de um sinal por meio de uma sequência de configuração de mão (CM) queexibe, convencionalmente, similaridade com letras do alfabeto do português, conforme explicitado na seção anterior. O empréstimo por transliteração, tratado por Faria-Nascimento (2009), divide-se em transliteração pragmática e empréstimo por transliteração lexicalizada.

No primeiro caso, trata-se de um recurso imediato em contextos que o emissor não conhece ou não se lembra do sinal. Esse recurso geralmente é temporário, pois essa língua tende a "fixar um referente designado por um 'sinal' lexicalizado que será definido na 
medida em que o referente for conceitualmente reconhecido pelos falantes" (FARIANASCIMENTO, 2009, p. 62). No segundo caso, representam-se palavras inteiras (A-L-HO para "alho"), palavras abreviadas (B-O para "boletim de ocorrência") ou por uma única letra associada a um dos seguintes movimentos:

(a) movimento vibratório da CM sobre o mesmo eixo (punho) com em ' $b$ ' para BOLÍVIA; ou (b) movimento circular no ar, no mesmo ponto da articulação datilológica, como em ' $\mathrm{v}$ ' para VESTIBULAR, ou (c) movimento horizontal retilíneo curto em direção oposta ao corpo (afastamento do corpo) como em 'c' para CUNHADO. (FARIANASCIMENTO, 2009, p. 65)

A constituição de uma série de sinais que nomeiam entidades com traços de estabilidade temporal se dá por meio do empréstimo por transliteração lexicalizada. Nesses casos, representa-se a maioria das letras que compõem a palavra em português, como se observa no sinal CD (Fig. 12).

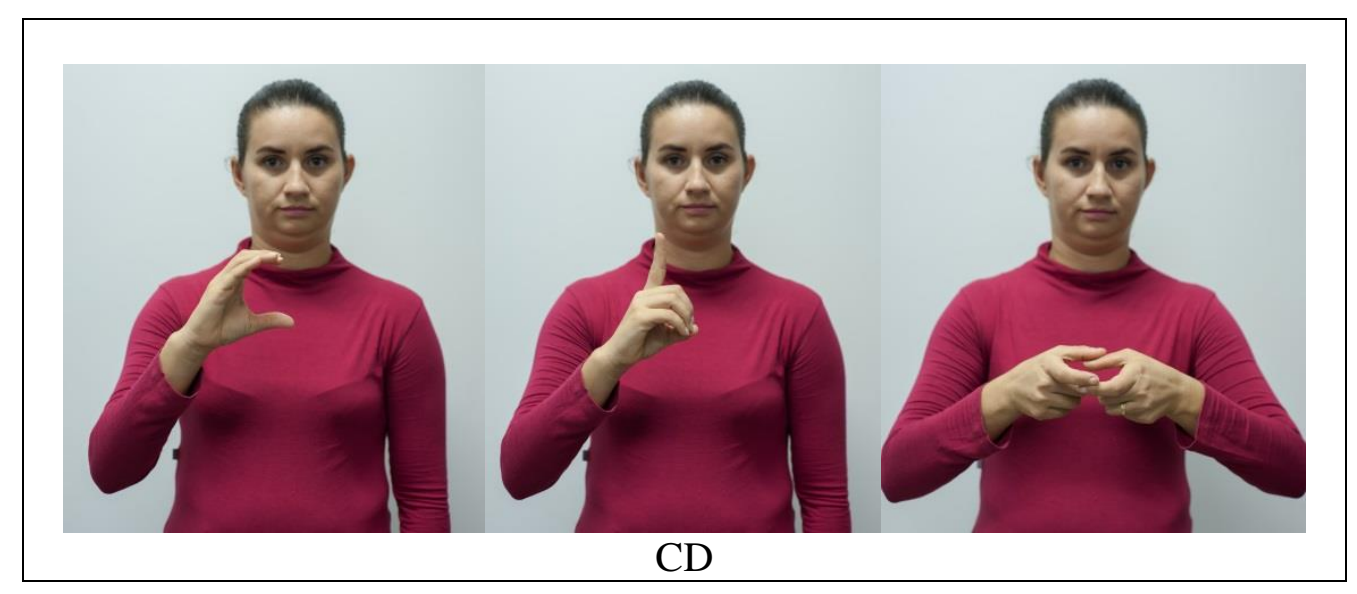

Figura 12. Ilustração do sinal CD.

Em CD, soletra-se C e D, dispondo as mãos, em seguida, em posição horizontal,com os dedos polegar e indicador estendidos, curvados, formando a letra C, e se tocando pelas pontas.Esse mesmo processo de produção é observado no sinal DVD (Digital Versatile Disc). 
Há sinais com traços de concretude que são representados por uma sequência de letras que constitui a palavra em português, conforme se observa nos sinais OVO e PAI (Fig. 13).

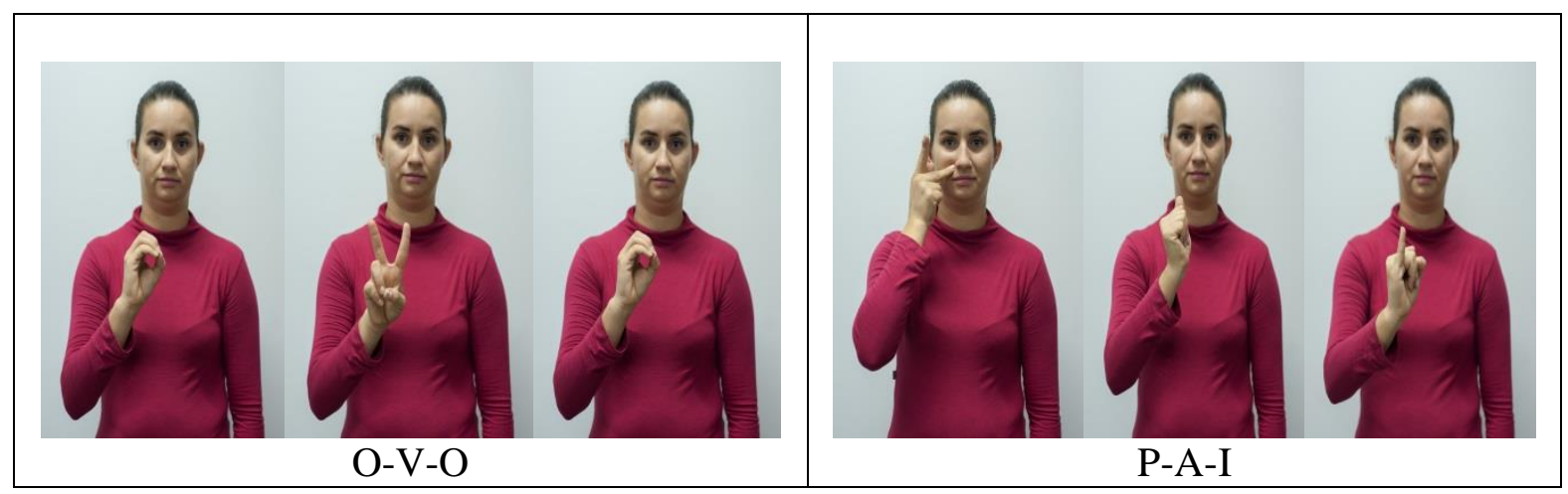

Figura 13. Ilustração dos sinais OVO e PAI.

Observa-se ainda que há sinais menos prototípicos em termos de compacidade e que sua constituição ocorre por meio da sequência de partes das letras que compõem a palavra em português, como nos exemplos MARÇO e MAIO (Fig. 14).

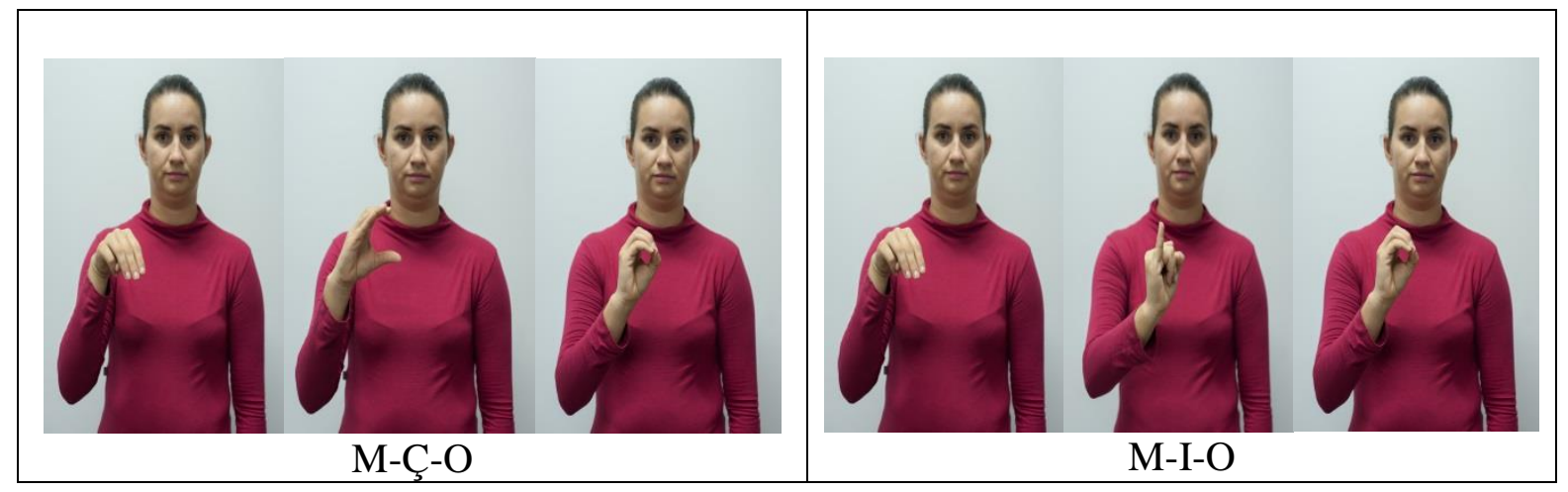

Figura 14. Ilustração dos sinais MARÇO e MAIO. 


\title{
Considerações
}

A partir dessas observações preliminares, sugerem-se três processos produtivos de sinais nocionalmente nomes na Libras. Embora seja possível descrever as particularidades constitutivas de cada processo, não é possível fixá-los com base nas características semânticas prototípicas das línguas orais, ou seja, os possíveis nomes em cada processo podem apresentar traços semânticos diversos.

É natural que línguas em contato exerçam influência uma sobre a outra, inclusive na criação lexical. Neste texto pode-se verificar que a língua oral está muito presente na língua de sinais, ou seja, dois dos três processos produtivos daqueles sinais nocionalmente nomes se caracterizam pelo empréstimo do português.

Supõe-se, portanto, que do ponto de vista da política linguística, o português exerce controle sobre a Libras e, por isso, valida a criação lexical da língua de sinais a partir de características constitutivas do léxico da língua oral. Nesse sentido, é provável que a língua de sinais busque "apoio" na língua oral, uma vez que se trata de uma língua com pouco tempo de reconhecimento legal no Brasil e, consequentemente, sem autonomia política para expansão lexical. Tais suposições devem ser consideradas e retomadas em reflexões posteriores para que se tenha uma melhor compreensão da situação política da Libras.

\begin{abstract}
This article aims to present considerations on signs in Brazilian Sign Language (Libras) that notionally correlate to nouns in Brazilian Portuguese. The observations were made based on prototypical semantic characteristics for the definition of the lexical category "noun", proposed by Givón (2001). When considering especially the visual-spatial modality of that language, dimension is suggested as a semantic criterion of relevance because it is through it that several entities are described. Three productive processes of signals, notionally nouns in this language are suggested based on their semantic characteristics: the spatial representation of entities, signs that insert the initial letter of the word in Portuguese in their form, and the dactylology as a resource for the formation of signs.
\end{abstract}

Keywords: Libras, Semantic characteristics, Nominal notion. 


\section{Resumen}

Este artículo tiene el objetivo de presentar algunos aspectos sobre las señas utilizadas en la Lengua de Señas Brasileña (Libras), que se relacionan nocionalmente con nombres del portugués brasileño. Las observaciones se basaron en las características semánticas prototípicas para la definición de la categoría lexical nombre, propuestas por Givón (2001). Al considerar especialmente la modalidad visuoespacial de esa lengua, se imagina la dimensión como criterio semántico de relevancia, pues es a través de ella que se describen varias entidades. Se sugierentres procesos productivos de señas, nocionalmente con nombres en esa lengua, con base en sus características semánticas: la representación espacial de las entidades, signos que insertan la letra inicial de la palabra en portugués en su forma y, la dactilología como recurso para la formación de señas.

Palabras-clave: Libras, Características semánticas, Concepto nominal.

\section{Referências}

FARIA-NASCIMENTO, Sandra Patrícia. Representações lexicais na Língua de Sinais Brasileira: uma proposta lexicográfica. 2009. 290 f. Tese (Doutorado em Linguística) Instituto de Letras, Universidade de Brasília, Brasília, 2009.

GIVÓN, Talmy. Syntax: a functional-typological introduction. vol. I e II. Amsterdam / Philadelphia: John Benjamin's Publishing Company, 2001.

NASCIMENTO, Cristiane Batista. Alfabeto manual da língua de sinais brasileira (LSB): uma fonte produtiva para importar palavras da língua portuguesa Trama, Cascavel, v. 7, n. 14, p. 33-55, 2011.

PIZZIO, Aline Lemos. A Tipologia Linguística e a Língua de Sinais Brasileira: elementos que distinguem nomes de verbos. 2011. 237 f. Tese (Doutorado em Linguística) - Centro de Comunicação e Expressão. Universidade Federal de Santa Catarina, Florianópolis, 2011.

QUADROS, R. M.; KARNOPP, L. B. Língua de sinais brasileira: Estudos linguísticos. Porto Alegre: Artmed, 2004.

SALLES, Heloísa Maria M. L. et al. Ensino de língua portuguesa para surdos: caminhos para a prática pedagógica, v. 1. Brasília: MEC, SEESP, 2004.

TAYLOR, John R. Cognitive grammar. New York: Oxford University Press, 2002.

TEIXEIRA, Vanessa Gomes. "A iconicidade e arbitrariedade na Libras". Revista Philologus, Rio de Janeiro, v. 20, p. 91-98, 2014. 
Nota

${ }^{1}$ Nossos agradecimentos a Leylenne Araújo Flores Romeiro por permitir o uso das imagens que ilustram os principais exemplos deste artigo.

Revista Sinalizar, Goiânia, v. 2, n.1, p. 5 - 23, jan. / jun., 2017. ISSN: 2448-0797. 